\title{
Evaluation of Some Properties of Acrylic Resin Denture Base Reinforced with Calcium Carbonate Nano-Particles
}

\author{
Jawad M. Mikael ${ }^{(1)}$; Salem Al-Samaraie ${ }^{(2)}$; Fahd S. Ikram ${ }^{(3)}$
}

Background and objectives: Radiolucency of poly methyl methacrylate denture base resin is of great concern, and many approaches have been used to make acrylic resin dentures more radiopaque.The purpose of this study was to prepare a modified heat cure ploy methyl methacrylate denture base resin by incorporation of different weight percentages $(2 \%, 3 \%, 4 \%, 5 \%$, and $6 \%)$ of $\mathrm{CaCO} 3$ nanofiller particles, to increase its radiopacity.

Materials and methods: $\mathrm{CaCO} 3$ nanofiller particles (coated with a special coupling agent) were dispersed and sonicated in the acrylic monomer (liquid) in different percentages, then mixed with acrylic powder. For each test 60 specimens were prepared, the specimens were divided into 6 groups (10 for each) coded I to VI. Group I was the control group (unmodified specimens), the remaining five groups were reinforced with $\mathrm{CaCO} 3$ nanoparticles to achieve loading of $2 \%, 3 \%, 4 \%, 5 \%$, and $6 \%$ by weight. Some physical properties were evaluated.

Results: There was a slight change of color of the acrylic, in groups II, III and IV, but there was an obvious color change of group V and VI. Also, there was a highly significant increase in the radiopacity in groups IV, $\mathrm{V}$ and $\mathrm{VI}$.

Conclusion: Addition of $4 \% \mathrm{CaCO} 3$ nanoparticles to the heat cure acrylic resin increases the radiopacity of the denture base significantly, without adverse effects on the color.

Key words: Acrylic resin, $\mathrm{CaCO} 3$, radio-opacity, color change

${ }^{(1)}$ B.D.S., M. Sc., Ph.D., Lecturer at the College of Dentistry- Hawler Medical University.

${ }^{(2)}$ B.D.S., M. Sc., Ph.D., Professor at the College of Dentistry- Baghdad University.

${ }^{(3)}$ B.D.S., M. Sc., Ph.D., Lecturer at the College of Dentistry- Hawler Medical University.

\section{Introduction}

Poly methyl methacrylate or acrylic is one of the most used materials for making a denture base that's why researchers always try to find the ways to make the qualities of acrylic better.

The acrylic used today is radiolucent, so in case of accidental ingestion, aspiration and traumatic impaction of dental appliance, their detection is will be very difficult and require invasive procedures as advanced imaging techniques, delay in localizing or removing the foreign body may be life threatening ${ }^{1}$. Many attempts have been tried to increase the radiopacity of acrylic denture base. It has been found that addition of $\mathrm{BaSO}_{4}$ particles, ${ }^{2} \mathrm{Ti}$ powder and $\mathrm{ZnO}_{2}{ }^{3}$ and $\mathrm{ZrO}_{2}$ nano-particles ${ }^{4}$ improved the radiopacity of PMMA acrylic resin significantly.

The biocompatibility of dental materials is an important consideration for the patient. Ideally a dental material that is to be used in the oral cavity should be harmless to all oral tissues, gingivae, mucosa, pulp and bone. Furthermore, it should contain no toxic, leachable, or diffusible substances. ${ }^{5}$ One of the most common spherical nanoscale fillers used in preparation of nanocomposites is $\mathrm{CaCO} 3 .^{6}$ 
Recently, the evaluation of the effect of nano- $\mathrm{CaCO}_{3}$ particles on thermal and mechanical properties of epoxy resin. It was revealed that epoxy resin filled with nano$\mathrm{CaCO}_{3}$ particles represents higher thermal stability and higher mechanical strength. ${ }^{7}$

The aim of this study was to incorporate Calcium Carbonate nanoparticles to PMMA denture base polymer resin, to evaluate the effects of this addition on radiopacity, and color stability of the denture base material. The inorganic $\mathrm{CaCO}_{3}$ nano-filler used in this study was coated with trymethoxysilylpropylmethacrylate (TMSPM) coupling agent.

\section{Materials and methods}

The study was consisted of six groups (I to VI), group I was the control group (unmodified specimens), the remaining five groups were reinforced with $\mathrm{CaCO} 3$ nanoparticles to achieve loading of $2 \%, 3 \%$, $4 \%, 5 \%$, and $6 \%$ by weight. for each property tested 60 specimens were prepared (10 for each group).

Radiopacity test. Sixty acrylic specimens with dimensions of $2.5 \mathrm{~mm}$ in the thickness 10 $\mathrm{mm}$ in width and $30 \pm 1 \mathrm{~mm}$ in length were prepared using conventional flasking and packing in gypsum moulds, (10 specimens for each group).

Aluminum step-wedge was constructed by cutting pure aluminum plate into desired shape and dimensions which consisted of 10 steppers starting from $1 \mathrm{~mm}$ thickness of aluminum with $1 \mathrm{~mm}$ increment in each step reaching to $10 \mathrm{~mm}$ at the last step. ${ }^{8}$

Twelve specimens (two for each group) were arranged over a wax plate of $10 \mathrm{~mm}$ thickness (the use of wax was to simulate the absorption and scattering media of the soft tissue). The aluminum step wedge was fixed beside the specimens for standardization of the density of the radiographic film. ${ }^{9}$

The wax plate on which the aluminum step wedge and the specimens were placed and kept over the exposure side of a $20.3 \mathrm{X}$ $25.4 \mathrm{~cm}$ cassette type kodak medical $\mathrm{x}$-ray film as shown in Figure 1.

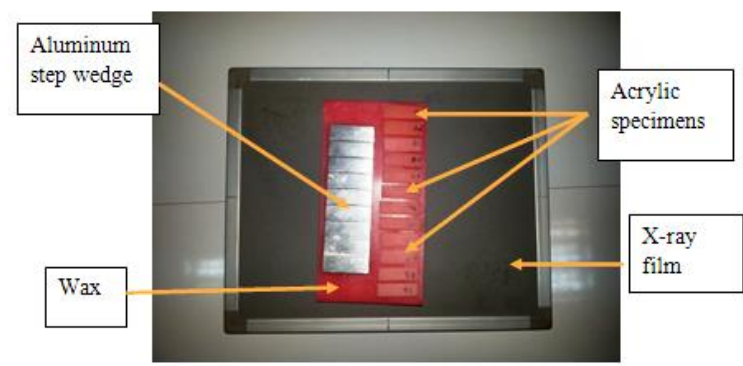

Figure 1: Acrylic specimens and aluminum step wedge over the wax plate and the $x$-ray film.

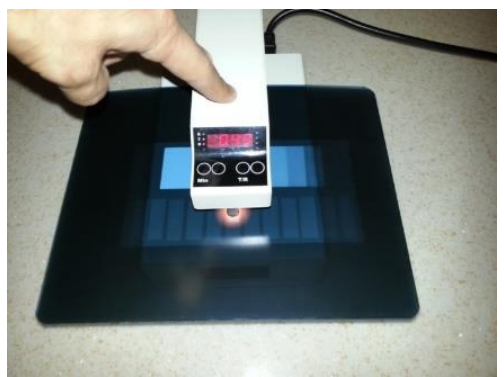

Figure 2: Light transmission densitometer used to measure the radiograph image density.

An x-ray machine type EVA-HF525 was used with 1-meter distance between the source of x-ray and specimens, the machine was operated at $30 \mathrm{kv}$ and $50 \mathrm{~mA}$ using 0.1 second exposure time as it is used for normal chest radiography.

The processing was done according the manufacturer's instructions by using automatic X-ray film processor (JP-33, Korea). A light transmission densitometer was used to measure the difference in the radiograph image density of all specimens with the control acrylic specimens and the aluminum step wedge. Three measurements in different areas of each specimen were taken, then the mean of them was calculated. The whole procedure was repeated five times with the use of different specimens, so that 10 specimens for each testing group were tested.

Color stability test. Sixty specimens (10 for each testing group) were prepared with dimensions ( $25 \times 4 \times 0.5) \mathrm{mm}$ in length, width 
and thickness respectively to fit the cuvette (specimen carrying chamber) of the spectrophotometer.

The color stability test was evaluated using two different methods, subjective and objective method.

The subjective method (visual inspection); according to the ADA specification no. 12, color stability of acrylic resin denture base inspection in north sky day-light. The visual inspection of color stability of the acrylic resin after addition of the $\mathrm{CaCO} 3$ nano-particles were assessed by 10 independent observers (dentists), each observer read the specimens and evaluated the color stability by visual inspection, the comparisons were made in the north sky day-light. During the visual inspection, the specimens were placed on a white background and they were graded for quantity of color change on a scale as follows:

No $=0$, Slight $=1$, Mild $=2$. Moderate $=3$, Severe $=4 .^{11}$

In the objective method (spectroscopic study) a spectrophotometer device was used to measure the light absorption of each specimen at 500 nanometer (nm).

When the specimens were placed in the cuvette and the light absorption was tested, the materials can be evaluated by visual

read-out device of the spectrophotometer displayed the amount of light absorption by both the specimen and the cuvette, so at the start the light absorption of the cuvette was measured before placing the specimens within the cuvette, in order to detect out the exact light absorption by the specimens only.

The light absorption of the sixty specimens (10 for each testing group) were measured using 500nm wave-length.

\section{Results}

Radiopacity test. Mean values of radiographic densities of control group and the testing groups is summarized in Table (1). The highest radio density mean value was recorded by control group (1.183) which does not contain the nanoparticles, while group VI which contains $6 \mathrm{wt} \% \mathrm{CaCO} 3$ nanoparticles recorded the lowest value (1.115) which means the most radio-opaque group as seen in Table (1).

The statistical analysis by one-way ANOVA showed that there was a highly significant difference among the testing groups, with a significant value of .000 , as shown in Table (1).

Table 1: Descriptive statistics, ANOVA test and LSD test for radio-density.

\begin{tabular}{|c|c|c|c|c|c|c|}
\hline Radio-density & $\begin{array}{c}\text { No of } \\
\text { Specimens }\end{array}$ & Mean & SD & Anova P-value & LSD & LSD P-value \\
\hline \multirow{3}{*}{ Group I } & \multirow{3}{*}{10} & \multirow{3}{*}{1.183} & \multirow{3}{*}{0.01059} & \multirow{10}{*}{0.000 (H.S) } & IXIV & \multirow{3}{*}{0.000} \\
\hline & & & & & IXV & \\
\hline & & & & & $\mathrm{IXVI}$ & \\
\hline \multirow[b]{2}{*}{ Group II } & \multirow[b]{2}{*}{10} & \multirow[b]{2}{*}{1.178} & \multirow[b]{2}{*}{0.00919} & & II XIV & \multirow{2}{*}{0.000} \\
\hline & & & & & $\mathrm{II} X \mathrm{~V}$ & \\
\hline \multirow{2}{*}{ Group III } & \multirow{2}{*}{10} & \multirow{2}{*}{1.176} & \multirow{2}{*}{0.00843} & & II XVI & \multirow{2}{*}{0.000} \\
\hline & & & & & III XIV & \\
\hline \multirow[b]{2}{*}{ Group IV } & \multirow[b]{2}{*}{10} & \multirow[b]{2}{*}{1.155} & \multirow{2}{*}{0.01080} & & III X V & \multirow[b]{2}{*}{0.000} \\
\hline & & & & & III X VI & \\
\hline Group V & 10 & 1.124 & 0.01838 & & IV XV & 0.000 \\
\hline
\end{tabular}




\begin{tabular}{|c|c|c|c|c|c|c|}
\hline Group VI & 10 & 1.115 & 0.01354 & & IV X VI & 0.000 \\
\hline
\end{tabular}

Although there was a regular increase in radiopacity of the specimens by increasing the amount of $\mathrm{CaCO} 3$ nanoparticles to PMMA, the LSD test showed that there was no significant improvement in radiopacities of group II and III, although there was a highly significant increase in radiopacities of group IV, V and VI, but still not radio-opaque enough according to international standards which accept radiopacity equivalent to $2 \mathrm{~mm}$ of Aluminum (2 $\mathrm{mm}$ thickness radiopacity was 0.71 ).

\section{Color stability test.}

A. Color stability test by visual method:

According to ADA specifications no. 12, color stability of PMMA resin denture base can evaluated by visual examination, accordingly the specimens were graded for quantity of color change on a scale as follows: No $=0$, Slight $=1$, Mild $=2$, Moderate $=3$ and severe $=4^{10}$. Statistical analysis by ANOVA showed a significant difference among the testing groups as seen in Table (2). It was found that addition of $2 \mathrm{wt} \%, 3 \mathrm{wt} \%$, and $4 \mathrm{wt} \%$ of $\mathrm{CaCO} 3$ nanoparticles are acceptable according to ADA specification no. 12 as there was slight change of the conventional color of PMMA resin. From the results, it appeared that addition of $5 \mathrm{wt} \%$ and $6 \mathrm{wt} \%$ $\mathrm{CaCO} 3$ nanoparticles will lead to unacceptable color change to PMMA resin denture base.

Table 2: The results of the color stability test by visual inspection.

\begin{tabular}{|c|c|c|c|}
\hline $\begin{array}{c}\text { Visual color } \\
\text { stability }\end{array}$ & No. of specimens & Mean & SD \\
\hline Group I & 10 & 0 & 0 \\
\hline Group II & 10 & 0.52 & 0.1932 \\
\hline Group III & 10 & 0.94 & 0.1897 \\
\hline Group IV & 10 & 1.08 & 0.1686 \\
\hline Group V & 10 & 1.6 & 0.2981 \\
\hline Group VI & 10 & 2.1 & 0.2160 \\
\hline
\end{tabular}

Table 3: The results of the color stability test by spectrophotometer

\begin{tabular}{|c|c|c|c|c|}
\hline $\begin{array}{c}\text { Color stability } \\
\text { spectrophotometer }\end{array}$ & No. of specimens & Mean & SD & ANOVA P-value \\
\hline Group I & 10 & 1.5274 & 0.0567 & 0.0394 \\
\hline Group II & 10 & 1.5721 & 0.000 (H.S) \\
\hline Group III & 10 & 1.5791 & 0.0246 \\
\hline
\end{tabular}




\begin{tabular}{|c|c|c|c|}
\hline Group V & 10 & 1.6126 & 0.0475 \\
\cline { 1 - 3 } Group VI & 10 & 1.6373 & 0.0313 \\
\hline
\end{tabular}

B. Color stability test by spectrophotometer

The descriptive statistics of color stability by spectroscopic study of the testing group revealed that group VI which contain $6 \mathrm{wt} \%$ $\mathrm{CaCO} 3$ nanoparticles showed the highest mean value, while the lowest mean value was recorded by the control group.

\section{Discussion}

In the present study $\mathrm{CaCO} 3$ nanoparticles had been selected as reinforcing nanofillers because it is white in color that is not expected to adversely affect the esthetic appearance of the acrylic denture base, also acted as an excellent reinforcing agent in other polymers like polypropylene, as well as due to its excellent biocompatibility. ${ }^{12}$

The $\mathrm{CaCO} 3$ nanofillers used in the present study were modified by surface coating with trimethoxysilyl propyl methacrylate (TMSPM) coupling agent, ${ }^{13}$ this is to enhance union between the nano-filler and the resin substrate. Moreover, the use of TMSMP as a silane coupling agent also enhances the homogenous dispersion of the nanofillers within the monomer. This finding was in agreement with Erjum $^{14}$ who stated that silanization of the nanofiller particles yield a better dispersion, eliminate aggregation and improve its compatibility with the organic polymer.

There have been instances of broken pieces of dentures being aspirated or swallowed; radiopacity is a desirable property to enable easy location of the denture fragments. Most denture base materials are radiolucent, that's why the production of radio-opaque denture base material become subject of prime importance for researchers.

In the present study, extra oral radiographs were used as it is more commonly used for emergency cases as a diagnostic mean.
ANOVA table showed showed a highly significance change in color stability among the testing groups with a value of significance (0.000), as shown in Table (3), indicating that there is a direct relationhip between the amount of $\mathrm{CaCO} 3$ nanoparticles and the amount of color change at wavelength level of 500

nm.

An aluminum step-wedge was used to standardize the densities of the exposed films because it has a linear absorption coefficient similar to that of enamel, also $10 \mathrm{~mm}$ thickness wax used under the radiographic film to simulate the absorbing and scattering media of soft tissues. ${ }^{8}$

The results of the current study showed that addition of $\mathrm{CaCO}_{3}$ nanofillers particles to PMMA resin denture base will decrease the radiographic densities which mean improving radiopacity. Furthermore, the transmission densitometer showed reduction in radiographic densities (increased radiopacity) with the increase in the amount of added $\mathrm{CaCO}_{3}$ nanofiller particles to PMMA resin, while the control group showed highest radiographic densities.

However, the results of the current study demonstrated that there was a non-significant increase in the radiopacities of group II and III, although there was a highly significant increase in radiopacities of groups IV, V and VI, but still not radio-opaque enough according to international standards, this finding can be explained that calcium has lower atomic number compared to other nanofillers like Zirconium and Titanium which produce more radiopacities when incorporated to PMMA.

In modern day dentistry, a large emphasis is laid over esthetics. Today, prostheses and restorations are made with precision so as to accurately match the surrounding oral 
structures. Color stability is the property of a material that allows color to be maintained over a period of time in a given environment, it is considered an important physical property of dental materials. ${ }^{15}$

The results of color stability by visual inspection showed that addition of $2 \mathrm{wt} \%, 3$ wt $\%$ and $4 \mathrm{wt} \%$ of $\mathrm{CaCO}_{3}$ nanofiller particles are acceptable according to ADA specification no. 12 as there was slight change of the conventional color of PMMA resin. These findings may be related to the white color of $\mathrm{CaCO}_{3}$ nanofiller particles as well as the small size of the nanoparticles, in addition to the well dispersion of the nanofiller particles within the polymer matrix. Other explanation of the slight change of the PMMA is the low percentage contents of the $\mathrm{CaCO}_{3}$ nanofiller particles within the polymer matrix.

The results of the spectrophotometer showed a highly significant change in color stability among the testing groups indicating that there is a direct relationship between the amount of $\mathrm{CaCO}_{3}$ nanoparticles and the amount of color change of the PMMA acrylic resin at wavelength of $500 \mathrm{~nm}$, showing the highest color change in group VI containing 6\% $\mathrm{CaCO}_{3}$ nanofiller particles and lowest color change in group II.

However, the tested acrylic resin specimens did not show any noticeable color change with the addition of $2-4 \% \mathrm{CaCO}_{3}$ nanofillers and the value which were measured by the spectrophotometer were not corresponded to any clinical detectable color alteration.

\section{Conclusion}

Within the limitations of this study, it can be concluded that addition of $4 \% \mathrm{CaCO}_{3}$ nanoparticles by weight will provide sufficient radiopacity to acrylic resin denture base without any noticeable changes in its color.

\section{References}

1- Mattie PA, Rawls HR, Cabasso L (1994). Development of radiopaque auto-polymerizing dental acrylic resin. J Prosthet Dent, 3(4), 213-218.
2- Wei G, Ma PX (2004). Structure and properties of nano-hybroxy apatite/ polymer composite scaffolds for bone tissue engineering. Biomaterials. 25, 4749.

3- Abdul-Ameer AS (2006). Evaluation of the changes in some properties of acrylic denture base material due to addition of radio-opaque fillers, M.Sc. Thesis, University of Baghdad / College of Dentistry.

4- Safi IN (2011). Evaluation of the effect of modified nano-fillers addition on some properties of heat cured acrylic resin denture base material. M.Sc. Thesis, University of Baghdad/ College of Dentistry.

5- Mousavinasab SM (2011). Biocompatibility of composite resins: Review article. J Dent Res, 8(5), 21-29.

6- Chen N, Wan C, Zhang Y (2004). Effect of nano$\mathrm{CaCO}_{3}$ on mechanical properties of PVC and PVC/Blendex blend. Journal of Polymer testing, 23, 169-174.

7- He H, Li K, Wang J, Dun G, Li Y, Wang J (2011). Study on thermal and mechanical properties of nanocalcium carbonate/epoxy composites, Mater Desig. 1-7.

8- Salem SA (1979). Reinforced denture base materials. Ph.D. Dissertation, University of Manchester.

9- Kaffe I, Littner MM, Kusoet ME (1984). Densitometric evaluation of intra-oral X-ray films. J Oral Surg, 57(3), 338-342.

10-ADA (American dental association) specification no. 12. (1999). Denture base polymer, Chicago, USA.

11-Al-Khafaji AH (2004). The effect of prepared denture cleansers on some properties of stained acrylic resin denture base material cured by two different techniques. M.Sc. thesis. University of Baghdad-College of dentistry.

12-Santoshkumar B, Prabakaran R, Ramya G, Virupaxy G, Joseph H, Vani R, Sudhakar B, Robert J, Govindarjan R (2011). Calcium Carbonate Nanoparticles: Synthesis, Characterization and Biocompatibility. Journal of Nanoscience and nanotechnology. 11(8), 6868-6874.

13-MK Nano (2012). Catalogue of nano particles, MK Impex Corporation, Ontario, Canada.

14-Erjun T, Cheng G, Pang X, Ma X, Xing F (2005). Synthesis of nano $\mathrm{ZrO}_{2} / \mathrm{PMMA}$ composite microsphere through emulsion polymerization and UVshielding property. J Colloid and polymer science, 284(4), 422-428.

15-Assuncao WG, Barao VA, Pita MS, Goiato MC (2009). Effect of polymerization methods and 
Jawad M. Mikael; Salem Al-Samaraie; Fahd S. Ikram

thermal cycling on color stability of acrylic resin

denture teeth. J Prosthet dent, 102, 385-392 